\title{
miR-23a/b promote tumor growth and suppress apoptosis by targeting PDCD4 in gastric cancer
}

\author{
Xiuting $\mathrm{Hu}^{1,6}$, Yanbo Wang ${ }^{1,6}$, Hongwei Liang ${ }^{1,6}$, Qian Fan ${ }^{2,6}$, Ruichi Zhu ${ }^{3}$, Jiayi Cui ${ }^{4}$, Weijie Zhang ${ }^{5}$, Ke Zen ${ }^{1}$, Chen-Yu Zhang ${ }^{1}$, \\ Dongxia Hou ${ }^{\star, 1}$, Zhen Zhou ${ }^{\star, 1}$ and Xi Chen ${ }^{\star, 1}$
}

\begin{abstract}
MicroRNAs (miRNAs) are short non-coding RNAs of 21-23 nucleotides that play important roles in virtually all biological pathways in mammals and in other multicellular organisms. miR-23a and miR-23b (miR-23a/b) are critical oncomiRs (miRNAs that are associated with human cancers) of gastric cancer, but their detailed roles in the initiation and progression of gastric cancer remain to be elucidated. In this study, we found that miR-23a/b were consistently upregulated in gastric cancer tissues. We then investigated the molecular mechanisms through which miR-23a/b contribute to gastric cancer and identified programmed cell death 4 (PDCD4) as a direct target gene of miR-23a/b. In contrast to the upregulated expression levels of miR-23a/b, PDCD4 protein levels were dramatically downregulated and inversely correlated with miR-23a/b in gastric cancer tissues. Moreover, we observed that cell apoptosis was increased by miR-23a/b inhibitors and decreased by miR-23a/b mimics in gastric cancer cells and that the restoration of PDCD4 expression attenuated the anti-apoptotic effects of miR-23a/b in gastric cancer cells, indicating that PDCD4 is a direct mediator of miR-23a/b functions. Finally, we showed that miR-23a/b significantly suppressed PDCD4 expression and enhanced tumor growth in a gastric cancer xenograft mouse model. Taken together, this study highlights an important role for $\mathrm{miR}-23 \mathrm{a} / \mathrm{b}$ as oncomiRs in gastric cancer through the inhibition of PDCD4 translation. These findings may shed new light on the molecular mechanism of gastric carcinogenesis and provide a new avenue for gastric cancer treatment.
\end{abstract}

Cell Death and Disease (2017) 8, e3059; doi:10.1038/cddis.2017.447; published online 5 October 2017

Gastric cancer is the fourth most frequently diagnosed cancer worldwide, which varies widely in different countries and presents the highest occurrence in Eastern Asia. ${ }^{1}$ Although several screening techniques (e.g., gastric endoscopy, barium meal photofluorography and serum pepsinogen) have been proposed as screening methods for the early detection of gastric cancer, most patients are diagnosed at an advanced stage with a dismal outcome. ${ }^{2}$ While some new drugs have been developed for the prevention and treatment of gastric cancer, ${ }^{3}$ most advanced gastric cancer patients continue to suffer a poor prognosis. The exact mechanisms contributing to the origin and development of gastric cancer remain complex and obscure, and it is important to explore the molecular basis of gastric cancer and to identify new therapeutic targets for this disease.

miRNAs are a class of small non-coding RNA molecules (21-23 nucleotides in length) that regulate gene expression at the post-transcriptional level. ${ }^{4,5}$ miRNAs bind targeted mRNAs at complementary sites in the 3 '-untranslated regions (3'-UTRs), thereby inhibiting the translation or favoring the destabilization of mRNAs, which depends on the degree of nucleotide pairing. ${ }^{6,7}$ Through this mechanism of action,
miRNAs regulate diverse cellular functions and play vital roles in a wide variety of physiological and pathological cellular processes. $^{8}$ Importantly, aberrant miRNA expression is observed in various human cancers, including gastric cancer. ${ }^{9}$ Furthermore, anomalous miRNAs can exert an enormous effect by suppressing oncogenes or tumor suppressors, thereby functioning as tumor-suppressive miRNAs or oncogenic miRNAs during carcinogenesis. Among the miRNAs correlated with tumorigenesis, miR-23a and miR-23b (herein referred to as $\mathrm{miR}-23 \mathrm{a} / \mathrm{b}$ ) are among the most important. miR-23a/b belong to the miR-23 27 24 cluster: miR-23a is located in the miR-23a $\sim 27 a \sim 24-2$ cluster within the $19 \mathrm{p} 13$ chromosomal region, whereas miR-23b is located in the miR-23b 27b 24-1 cluster within the 9q22 chromosomal region. ${ }^{10,11}$ Notably, miR-23a/b are enhanced in acute lymphoblastic leukemia, acute myeloid leukemia, bladder cancer, glioblastoma, pancreatic cancer, uterine leiomyoma, hepatocellular carcinoma and gastric cancer. ${ }^{12-17}$ However, although several papers regarding the association of miR-23a/ b with cancer have been published, the detailed roles of $\mathrm{miR}-23 \mathrm{a} / \mathrm{b}$ in the initiation and progression of gastric cancer remains largely unknown. The aim of this study was to

\footnotetext{
${ }^{1}$ State Key Laboratory of Pharmaceutical Biotechnology, School of Life Sciences, Jiangsu Engineering Research Center for MicroRNA Biology and Biotechnology, NJU Advanced Institute for Life Sciences (NAILS), School of Life Sciences, Nanjing University, 163 Xianlin Road, Nanjing 210023, Jiangsu, China; ${ }^{2}$ Department of Lymphoma, National Clinical Research Center of Cancer, Key Laboratory of Cancer Prevention and Therapy, Tianjin Medical University Cancer Institute and Hospital, Tianjin 300060, China; ${ }^{3}$ Hong Kong University of Science and Technology, Clear Water Bay, Kowloon, Hong Kong, China; ${ }^{4}$ Department of Microbiology, Harbin Medical University, Heilongjiang Provincial Key Laboratory for Infection and Immunity, Key Laboratory of Etiology of Heilongjiang Province Education Bureau, Harbin, China and ${ }^{5}$ Department of General Surgery, Affiliated Drum Tower Hospital of Nanjing University Medical School, 321 Zhongshan Road, Nanjing, Jiangsu 210008, China

${ }^{*}$ Corresponding author: D Hou or Z Zhou or X Chen, State Key Laboratory of Pharmaceutical Biotechnology, Jiangsu Engineering Research Center for MicroRNA Biology and Biotechnology, Advanced Institute for Life Sciences (NAILS), School of Life Sciences, Nanjing University, 163 Xianlin Road, Nanjing, Jiangsu 210093, China.

Tel: (86)25 89681323; Fax: (86)25 89680245; E-mail: dxhou128@nju.edu.cn or zhenzhou@nju.edu.cn or xichen@nju.edu.cn

${ }^{6}$ These authors contributed equally to this work.

Received 04.8.16; revised 11.6.17; accepted 12.7.17; Edited by G Ciliberto
} 
evaluate the association of $\mathrm{miR}-23 \mathrm{a} / \mathrm{b}$ expression with gastric cancer and to explore the potential novel target genes of $\mathrm{miR}-23 \mathrm{a} / \mathrm{b}$.

In this study, we found that miR-23a/b levels were consistently upregulated in gastric cancer tissues. Subsequently, we showed that miR-23a/b enhanced tumor growth in a gastric cancer xenograft mouse model. Furthermore, we identified potential target genes of $\mathrm{miR}-23 \mathrm{a} / \mathrm{b}$ and found that miR-23a/b inhibit the apoptosis of gastric cancer cells by directly targeting an important tumor suppressor, programmed cell death 4 (PDCD4).

\section{Results}

$\mathrm{miR}-23 \mathrm{a} / \mathrm{b}$ are upregulated in gastric cancer tissues. We first determined the expression patterns of $\mathrm{miR}-23 \mathrm{a} / \mathrm{b}$ in human gastric cancer tissues. By measuring the expression levels of miR-23a/b in 10 pairs of gastric cancer tissues and normal adjacent tissues with quantitative RT-PCR, we found that $\mathrm{miR}-23 \mathrm{a} / \mathrm{b}$ levels were consistently increased in gastric cancer tissues compared with non-cancerous tissues (Figure 1). Moreover, we downloaded the miRNA expression data from The Cancer Genome Atlas (TCGA) website and analyzed the expression profiles of miR-23a/b in 42 normal tissues and 476 gastric cancer tissues. The results indicated again that $\mathrm{miR}-23 \mathrm{a} / \mathrm{b}$ were upregulated in gastric cancer tissues (Supplementary Figure 1).

Prediction of PDCD4 as a target gene of $\mathrm{miR}-23 \mathrm{a} / \mathrm{b}$. To explore the molecular mechanism by which miR-23a/b contributes to gastric cancer progression, three computational algorithms, TargetScan, ${ }^{18} \operatorname{PicTar}^{19}$ and miRanda, ${ }^{20}$ were used in combination to search for potential targets of $\mathrm{miR}-23 \mathrm{a} / \mathrm{b}$. Among the candidates, PDCD4, a potent tumor suppressor gene that is frequently downregulated in human cancers, ${ }^{21,22}$ was predicted to be a miR-23a/b target by all three of the algorithms and was selected for further experimental verification. The predicted interaction between $\mathrm{miR}-23 \mathrm{a} / \mathrm{b}$ and the target site in the PDCD4 $3^{\prime}-U T R$ is illustrated in Figure 2a. The $3^{\prime}$-UTR of PDCD4 contains one conserved binding site for $\mathrm{miR}-23 \mathrm{a} / \mathrm{b}$. There was perfect base-pairing between the seed region (the seed sequence that encompasses the first 2-8 bases of the mature miRNA 5' end) and the cognate target. The minimum free energy value of the hybrid was $-22.1 \mathrm{kcal} / \mathrm{mol}$, which is well within the range of genuine miRNA-target pairs.

\section{Detection of inverse correlations between $\mathrm{miR}-23 \mathrm{a} / \mathrm{b}$ and} PDCD4 protein levels in gastric cancer tissues. Since miRNAs are generally thought to have an opposite expression pattern to that of their targets, ${ }^{5}$ we next investigated whether $\mathrm{miR}-23 \mathrm{a} / \mathrm{b}$ expression was inversely correlated with PDCD4 expression in gastric cancer tissues. We measured the expression pattern of PDCD4 in the same 10 pairs of gastric cancer tissues and normal adjacent tissues. PDCD4 protein levels were consistently reduced in gastric cancer tissues (Figures 2b and c). In contrast, PDCD4 mRNA levels did not significantly differ between the cancerous and non-cancerous tissues (Figure 2d), which is in accordance with a posttranscriptional mechanism that is involved in the regulation of PDCD4. Immunohistochemical staining of PDCD4 and Ki-67 in gastric cancer tissues and normal adjacent tissues also revealed the presence of higher proliferative activity (indicated by the staining intensity of Ki-67-positive cells) but lower
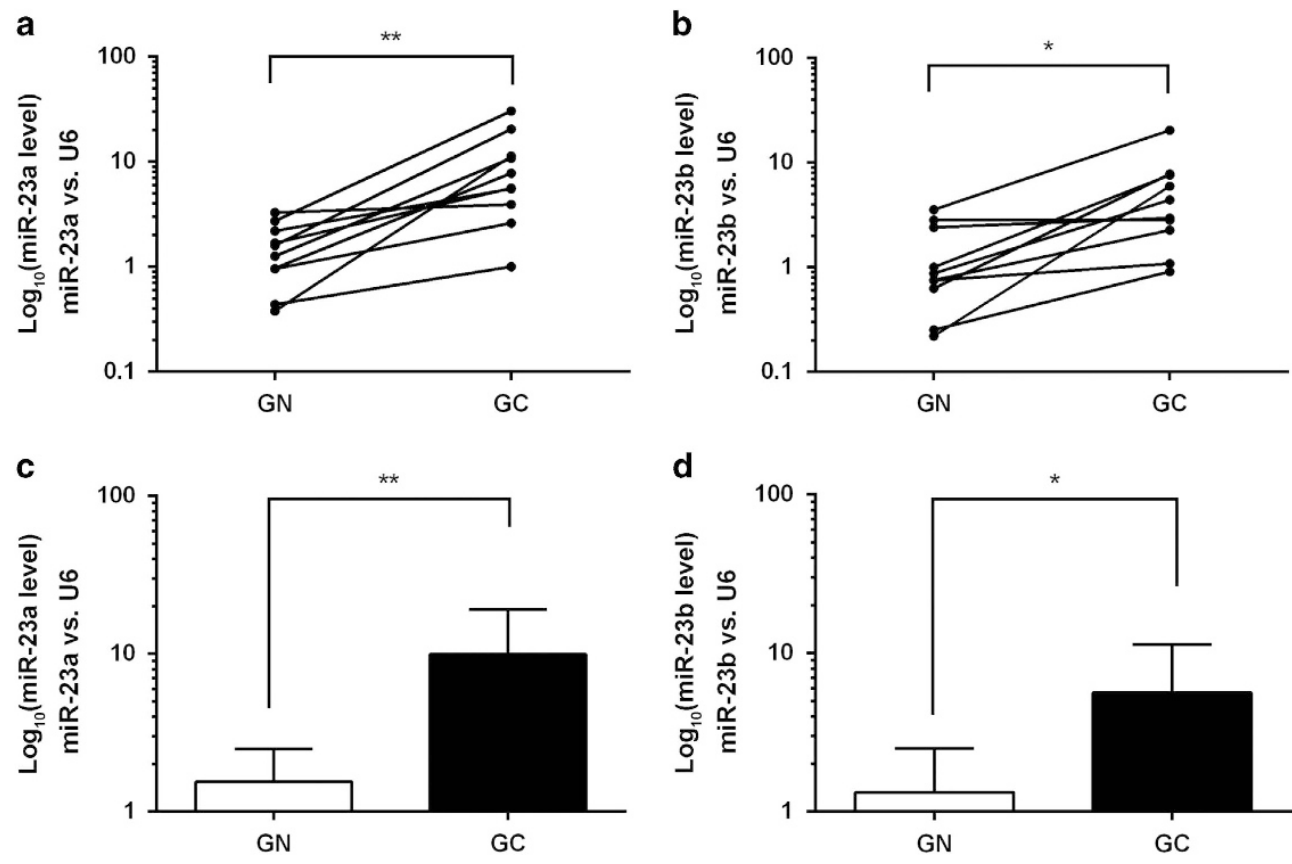

Figure 1 Expression levels of miR-23a/b in gastric cancer tissues. (a,b) Quantitative RT-PCR analysis of the individual alteration of miR-23a/b in 10 pairs of gastric cancer tissue (GC) compared with matched normal adjacent tissue (GN) samples. (c,d) Quantitative RT-PCR analysis of the mean expression levels of miR-23a/b in 10 pairs of gastric cancer tissue (GC) and matched normal adjacent tissue (GN) samples. Each bar represents the mean \pm SD values. $\left({ }^{\star} P<0.05 ;{ }^{* \star} P<0.01\right)$ 
a

5'UTR

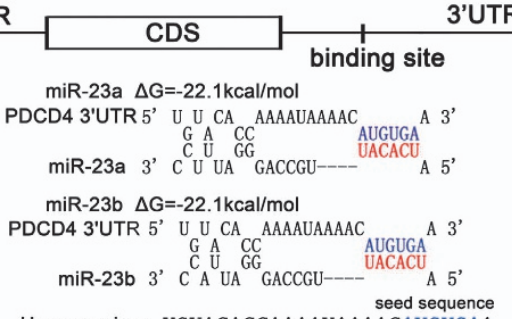

Homo sapiens UGUACACCAAAAUAAAACAUGUGAA

Pan troglodytes UGUACACCAAAAUAAAACAUGUGAA

Macaca mulatta UGUACACCAAAAUAAAACAUGUGAA

C

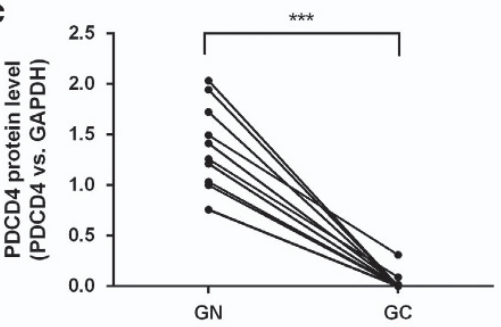

d

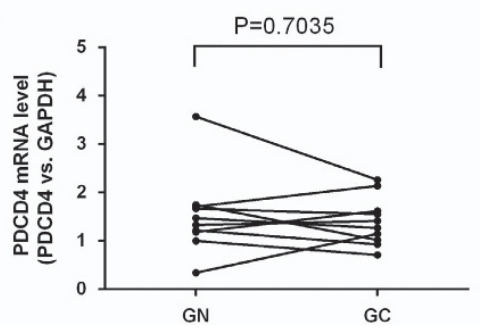

b

PDCD4

GAPDH
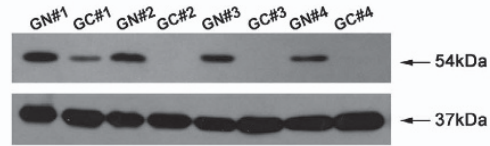

PDCD4

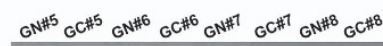

GAPDH
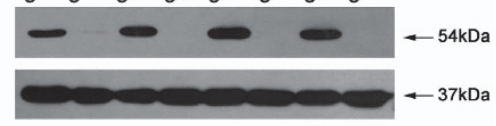

$4--54 \mathrm{kDa}$

GAPDH $\leftarrow 37 \mathrm{kDa}$
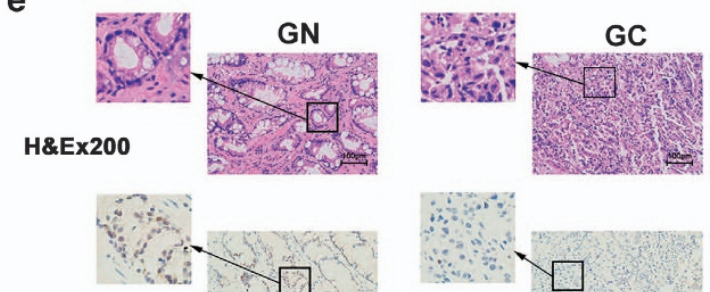

PDCD4×200
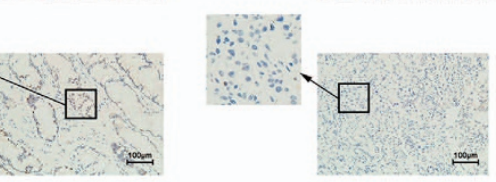
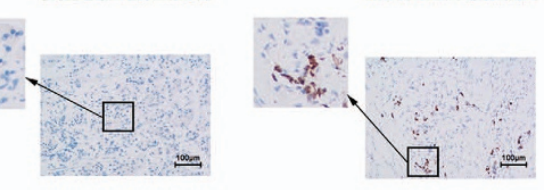

Figure 2 PDCD4 was predicted as a target of miR-23a/b and was downregulated in gastric cancer tissues. (a) Schematic description of the hypothetical duplexes formed by the interaction between the binding sites in the PDCD4 3'-UTR (top) and miR-23a/b (bottom). The predicted free energy value of each hybrid is indicated. The seed sequences and seed recognition sites are indicated in red and blue, respectively, and all nucleotides in these regions are highly conserved in several species. (b,c) Western blotting analysis of PDCD4 protein levels in 10 pairs of GC and GN samples. (b) representative image; (c) quantitative analysis. (d) Quantitative RT-PCR analysis of PDCD4 mRNA levels in the same 10 pairs of GC and GN samples. (e) Representative H\&E-stained, PDCD4-stained and Ki-67-stained sections of the GC and GN samples. ( ${ }^{\star \star \star} P<0.001$ )

PDCD4 levels (indicated by the staining intensity of PDCD4positive cells) in the gastric cancer tissues (Figure 2e).

Validation of PDCD4 as a direct target of $\mathrm{miR}-23 \mathrm{a} / \mathrm{b}$. The correlation between $\mathrm{miR}-23 \mathrm{a} / \mathrm{b}$ and PDCD4 was further examined by evaluating PDCD4 expression levels in two human gastric cancer cell lines, MKN-45 and AGS, after overexpression or knockdown of miR-23a/b. As anticipated, cellular miR-23a/b levels were significantly increased when MKN-45 and AGS cells were transfected with miR-23a/b mimics and were decreased when treated with $\mathrm{miR}-23 \mathrm{a} / \mathrm{b}$ antisenses (Figure 3a). Consequently, the protein levels of PDCD4 were significantly reduced by the introduction of $\mathrm{miR}-23 \mathrm{a} / \mathrm{b}$ mimics in MKN-45 and AGS cells, whereas $\mathrm{miR}-23 \mathrm{a} / \mathrm{b}$ antisenses significantly increased the PDCD4 protein levels (Figures $3 b$ and $c$ ). To determine the level at which $\mathrm{miR}-23 \mathrm{a} / \mathrm{b}$ regulate PDCD4 expression, we repeated the above experiments and examined the expression of PDCD4 mRNA after transfection. Overexpression or knockdown of miR-23a/b did not affect the mRNA levels of PDCD4 (Figure $3 d$ ). These results demonstrated that miR-23a/b specifically regulate PDCD4 protein expression at the posttranscriptional level, which is the most common mechanism for animal miRNAs.

To confirm that $\mathrm{miR}-23 \mathrm{a} / \mathrm{b}$ directly target the presumed binding site in the PDCD4 $3^{\prime}$-UTR and negatively regulate PDCD4 expression, a luciferase reporter assay was performed. The PDCD4 3'-UTR containing the presumed miR$-23 a / b$ binding site was fused downstream of the firefly luciferase gene in a reporter plasmid. The recombination plasmid was co-transfected into HEK293T cells along with $\mathrm{miR}-23 \mathrm{a} / \mathrm{b}$ mimics. As expected, overexpression of $\mathrm{miR}-23 \mathrm{a} / \mathrm{b}$ resulted in $\sim 50 \%$ reduction of luciferase reporter activity (Figure 3e). Furthermore, we introduced a point mutation into the corresponding complementary site in the PDCD4 $3^{\prime}$-UTR to disrupt the predicted $\mathrm{miR}-23 \mathrm{a} / \mathrm{b}$ binding site. The mutated luciferase reporter was unaffected by overexpression of $\mathrm{miR}-23 \mathrm{a} / \mathrm{b}$ (Figure 3e). This finding indicated that the binding site of PDCD4 strongly contributes to the miRNA-mRNA interaction. In conclusion, our results demonstrated that miR-23a/b directly bind to the $3^{\prime}-U T R$ of the PDCD4 transcript to suppress PDCD4 expression. 


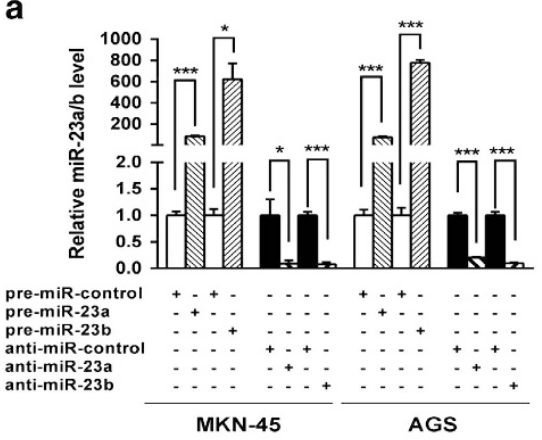

d

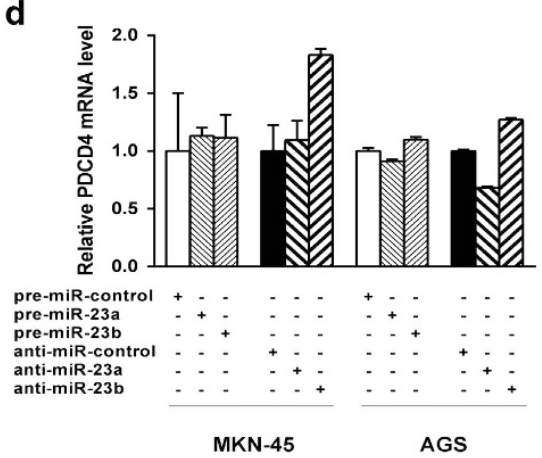

b

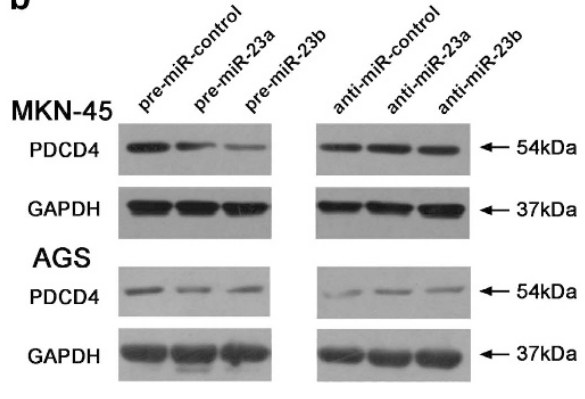

e

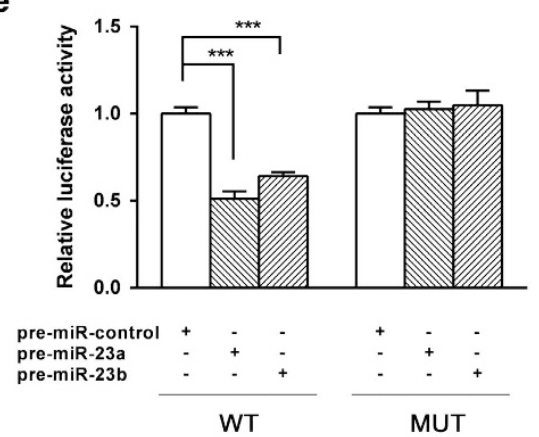

C

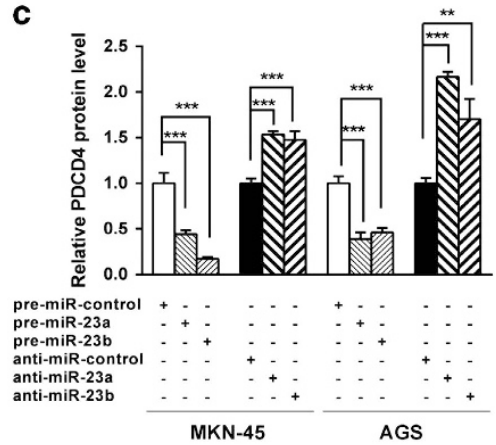

Figure 3 PDCD4 was a direct target of miR-23a/b. (a) Quantitative RT-PCR analysis of miR-23a/b levels in MKN-45 and AGS cells transfected with equal doses of premiR-23a/b, anti-miR-23a/b or scrambled negative control RNAs (pre-miR-control or anti-miR-control). (b,c) Western blotting analysis of PDCD4 protein levels in MKN-45 and AGS cells transfected with equal doses of the pre-miR-23a/b, anti-miR-23a/b or scrambled negative control RNAs. (b) representative image; (c) quantitative analysis. (d) Quantitative RT-PCR analysis of PDCD4 mRNA levels in MKN-45 and AGS cells transfected with equal doses of pre-miR-23a/b, anti-miR-23a/b or scrambled negative control RNAs. (e) Direct recognition of the PDCD4 $3^{\prime}$-UTR by miR-23a/b. Firefly luciferase reporters containing either wild-type (WT) or mutant (MUT) miR-23a/b binding sites in the PDCD4 3'-UTR were co-transfected into HEK293T cells along with equal doses of pre-miR-23a/b or pre-miR-control. The cells were assayed using a luciferase assay kit $24 \mathrm{~h}$ post-transfection. Firefly luciferase values were normalized to $\beta$-gal activity, and the results were calculated as the ratio of firefly luciferase activity in the miR-23a/b-transfected cells normalized to the premiR-control-transfected cells. $\left({ }^{\star} P<0.05 ;{ }^{* *} P<0.01 ;{ }^{* * *} P<0.001\right)$

miR-23a/b suppress apoptosis in gastric cancer cells by inhibiting PDCD4. Because PDCD4 is a well-known proapoptotic gene, ${ }^{23}$ we investigated whether miR-23a/b may suppress gastric cell apoptosis by silencing PDCD4. We first investigated the effects of $\mathrm{miR}-23 \mathrm{a} / \mathrm{b}$ on $\mathrm{MKN}-45$ cell apoptosis via flow cytometry. The apoptosis assay showed that the percentage of apoptotic cells was significantly lower in cells transfected with miR-23a/b mimics but was higher in cells transfected with miR-23a/b antisenses (Figures $4 a$ and b). Thus, miR-23a/b function as anti-apoptotic factors in gastric cancer cells. Subsequently, we investigated whether the knockdown or overexpression of PDCD4 would impact apoptosis in MKN-45 cells. To knockdown PDCD4, a siRNA sequence targeting human PDCD4 ORF was designed and transfected into MKN-45 cells. For the overexpression of PDCD4, a plasmid designed to specially express the fulllength ORF of PDCD4 without the miR-23a/b-responsive $3^{\prime}$ UTR was constructed and transfected into MKN-45 cells. The efficiency of knockdown or overexpression of PDCD4 is demonstrated in Supplementary Figure 2. As anticipated, transfecting PDCD4 siRNA markedly decreased the percentage of apoptotic cells when compared to the cells transfected with control siRNA, whereas transfecting the PDCD4overexpression plasmid increased cell apoptosis (Supplementary Figure 3). Thus, the inhibition of cell apoptosis by PDCD4 knockdown was similar to that elicited by $\mathrm{miR}-23 \mathrm{a} / \mathrm{b}$ overexpression, further indicating that $\mathrm{miR}-23 \mathrm{a} / \mathrm{b}$ and PDCD4 have opposing effects on cell apoptosis.

To investigate if $\mathrm{miR}-23 \mathrm{a} / \mathrm{b}$ may regulate the apoptosis of gastric cancer cells through a PDCD4-dependent manner, we co-transfected MKN cells with miR-23a/b mimics and PDCD4overexpression plasmid. Compared with cells transfected with $\mathrm{miR}-23 \mathrm{a} / \mathrm{b}$ mimics plus control plasmid, the cells transfected with $\mathrm{miR}-23 \mathrm{a} / \mathrm{b}$ mimics plus PDCD4-overexpression plasmid exhibited a significantly higher PDCD4 protein level (Figures $4 \mathrm{c}$ and $\mathrm{d}$ ), suggesting that the overexpression of miR-23a/b-resistant PDCD4 was sufficient to rescue the suppression of PDCD4 by $\mathrm{miR}-23 \mathrm{a} / \mathrm{b}$. Consequently, MKN-45 cells simultaneously transfected with miR-23a/b mimics and the PDCD4-overexpression plasmid showed significantly higher apoptotic rates than the cells transfected with $\mathrm{miR}-23 \mathrm{a} / \mathrm{b}$ mimics plus control plasmid (Figures $4 \mathrm{a}$ and b), suggesting that the overexpression of miR-23a/b-resistant PDCD4 was sufficient to attenuate the anti-apoptotic effects of $\mathrm{miR}-23 \mathrm{a} / \mathrm{b}$.

Apoptosis is orchestrated by Caspases, a family of cysteine proteases that cleave their substrates on the carboxy-terminal side of specific aspartic acid residues. ${ }^{24}$ Previous study has shown that introduction of PDCD4 induced the cleavage of CASP9, 3, 6, 7 and PARP in tumor cells. ${ }^{25}$ To further validate that $\mathrm{miR}-23 \mathrm{a} / \mathrm{b}$ can suppress gastric cell apoptosis by regulating $\mathrm{PDCD} 4$, we investigated the effects of $\mathrm{miR}-23 \mathrm{a} / \mathrm{b}$ 


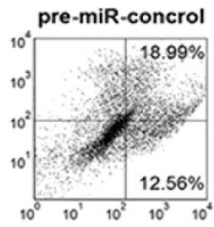

anti-miR-control

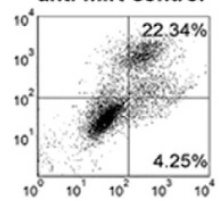

pre-miR-control

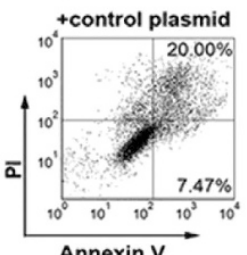

Annexin $\mathrm{V}$

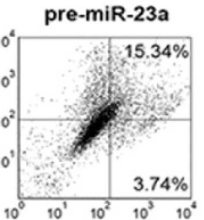

anti-miR-23a

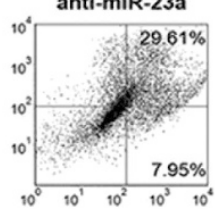

pre-miR-23a

+pre-miR-23b

+ control plasmid

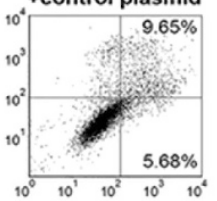

$10^{3} \quad 10^{4}$

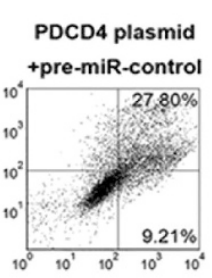

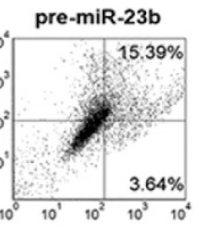

anti-miR-23b

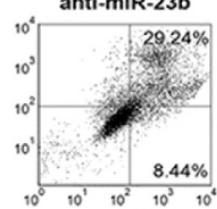

pre-miR-23a

+pre-miR-23b
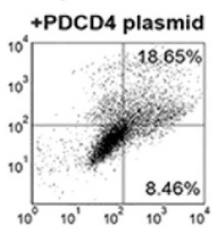

b

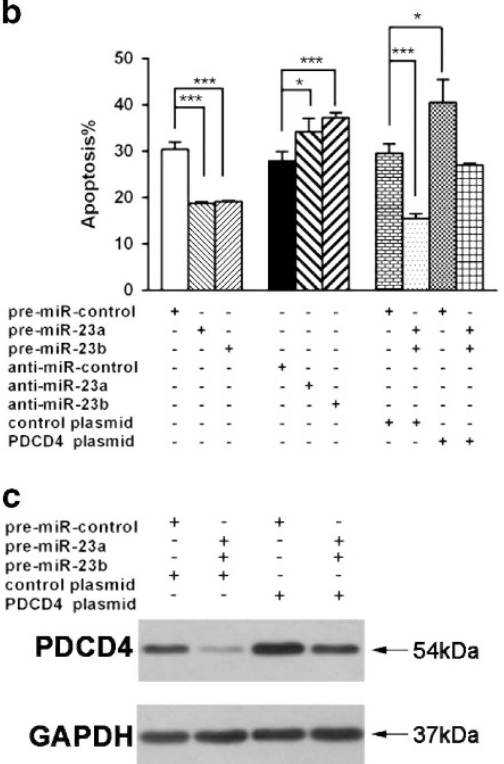

e
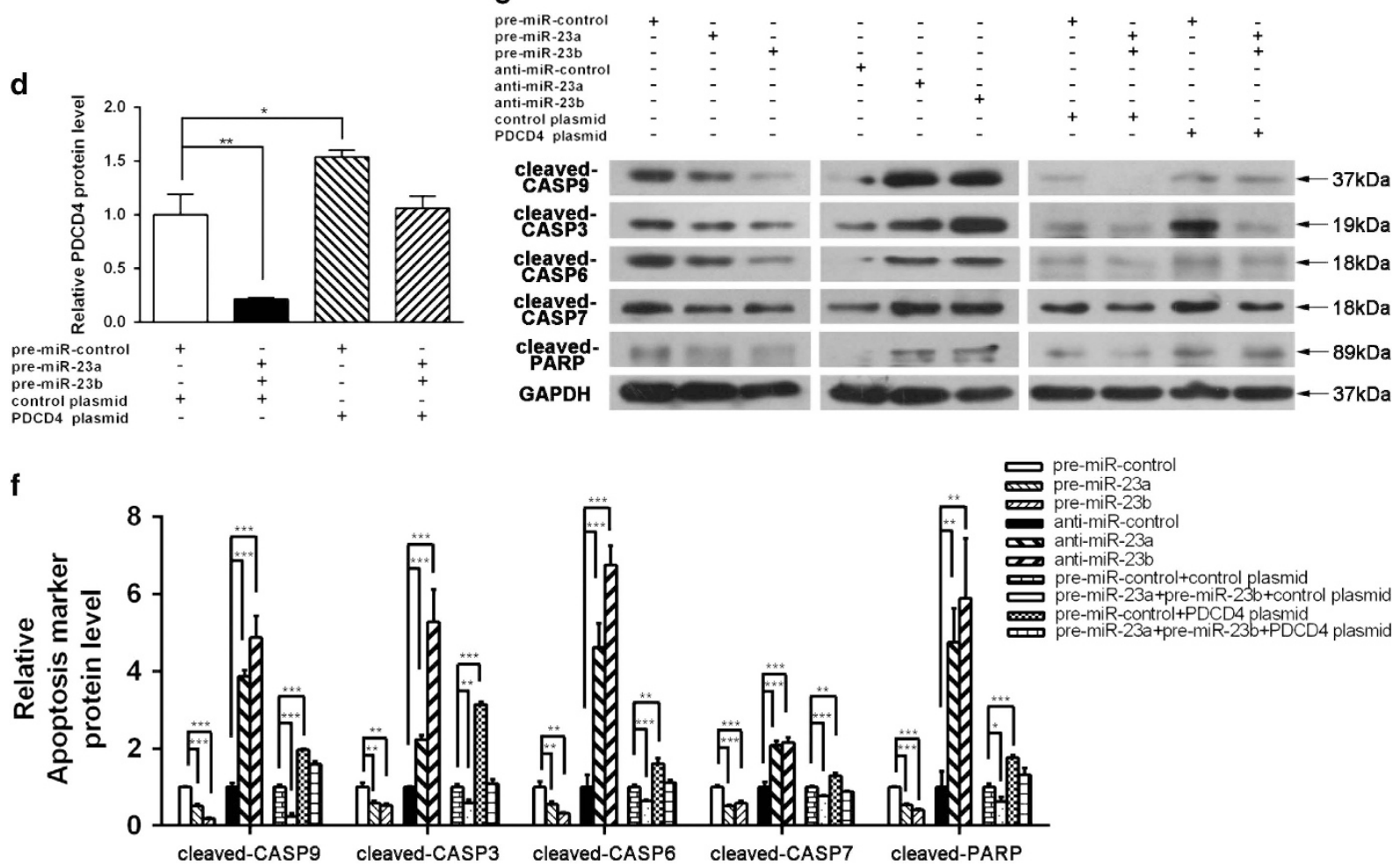

Figure 4 Effects of miR-23a/b and PDCD4 on the apoptosis of gastric cancer cells. (a,b) Apoptosis assays were performed $24 \mathrm{~h}$ after the transfection of MKN-45 cells with equal doses of pre-miR-23a/b, anti-miR-23a/b or scrambled negative control RNAs (pre-miR-control or anti-miR-control), or with equal doses of pre-miR-control plus control plasmid, pre-miR-23a/b plus control plasmid, pre-miR-control plus PDCD4-overexpression plasmid or pre-miR-23a/b plus PDCD4-overexpression plasmid. (a) representative image; (b) quantitative analysis. (c,d) Western blotting analysis of PDCD4 protein levels in MKN-45 cells transfected with equal doses of pre-miR-control plus control plasmid, premiR-23a/b plus control plasmid, pre-miR-control plus PDCD4-overexpression plasmid or pre-miR-23a/b plus PDCD4-overexpression plasmid. (c) representative image; (d) quantitative analysis. (e,f) Western blotting analysis of the levels of cleaved CASP9, 3, 6, 7 and PARP in MKN-45 cells transfected with equal doses of pre-miR-23a/b, antimiR-23a/b or scrambled negative control RNAs (pre-miR-control or anti-miR-control), or with equal doses of pre-miR-control plus control plasmid, pre-miR-23a/b plus control plasmid, pre-miR-control plus PDCD4-overexpression plasmid or pre-miR-23a/b plus PDCD4-overexpression plasmid. (e) representative image; (f) quantitative analysis. $\left({ }^{\star} P<0.05 ;{ }^{* \star} P<0.01 ;{ }^{* \star *} P<0.001\right)$ 
and PDCD4 on several well-characterized biochemical markers for apoptosis, including cleaved-CASP9, 3, 6, 7 and PARP. As anticipated, transfection of $\mathrm{miR}-23 \mathrm{a} / \mathrm{b}$ mimics reduced the cleavage of CASP9, 3, 6, 7 and PARP in MKN-45 cells, whereas transfection of miR-23a/b antisenses induced the cleavage of CASP9, 3, 6, 7 and PARP (Figures 4e and f). When MKN-45 cells were simultaneously transfected with miR-23a/b mimics plus PDCD4-overexpression plasmid, restoration of PDCD4 expression decreased the effects of $\mathrm{miR}-23 \mathrm{a} / \mathrm{b}$-mediated suppression of the cleavage of CASP9, 3, 6, 7 and PARP in MKN-45 cells (Figures $4 \mathrm{e}$ and f). In summary, as miR-23a/b and PDCD4 had opposite expression patterns and biological functions in gastric cancer cells, it is quite possible that miR-23a/b suppress apoptosis in gastric cancer cells by silencing PDCD4.

miR-23a/b function as oncomiRs in gastric cancer. We next evaluated the biological effects of miR-23a/b on gastric tumorigenesis in a xenograft mouse model. The human gastric cancer cell line MKN-45 was infected with a control lentivirus or lentiviruses to overexpress miR-23a or miR-23b. The efficient overexpression of $\mathrm{miR}-23 \mathrm{a} / \mathrm{b}$ by lentiviral infection is shown in Supplementary Figure 4A. Overexpression of miR-23a/b by lentiviral transfection reduced PDCD4 protein levels in MKN-45 cells (Supplementary Figure 4B and $4 \mathrm{C})$. Then, infected MKN-45 cells were subcutaneously implanted into 6-week-old SCID mice, and tumor growth was evaluated at day 25 after cell implantation (Figure 5a). A significant increase in the size and weight of the tumors was observed in the miR-23a/b-overexpressing group compared to the control group (Figures $5 b$ and $c$ ). Subsequently, total RNA was extracted from tumors and used to evaluate the expression levels of $\mathrm{miR}-23 \mathrm{a} / \mathrm{b}$. After 25 days of xenograft growth in vivo, tumors from the miR-23a/b-overexpressing groups showed significant increase in $\mathrm{miR}-23 \mathrm{a} / \mathrm{b}$ expression compared to tumors from the control group (Figure $5 d$ ). Likewise, tumors from the mice infected with miR-23a/boverexpressing $\mathrm{MKN}-45$ cells displayed reduced PDCD4 protein levels, but not mRNA levels, compared to tumors from the control group (Figures $5 \mathrm{e}-\mathrm{g}$ ). Furthermore, tumor tissues were embedded in paraffin and then stained with $H \& E$ for histology examination. The results revealed more cell mitosis in the miR-23a/b-overexpressing groups compared to the control group (Figure 5h). Immunohistochemical staining also revealed the presence of lower levels of PDCD4 in the groups implanted with miR-23a/b-overexpressing cells (Figures $5 \mathrm{~h}$ and i). Finally, the proliferative activity and apoptosis activity of the tumor cells were assessed via immunohistochemical staining of Ki-67 or cleaved-CASP3, respectively. The tumor cell proliferation rate, as measured by the staining intensity of Ki-67-positive cells, was increased in tumors from the miR-23a/b-overexpressing groups (Figures $5 \mathrm{~h}$ and i). In contrast, the tumor cell apoptosis rate, as measured by the staining intensity of cleaved-CASP3-positive cells, was decreased in tumors from the $\mathrm{miR}-23 \mathrm{a} / \mathrm{b}$-overexpressing groups (Figures $5 \mathrm{~h}$ and $\mathrm{i}$ ).

\section{Discussion}

Recently, miRNAs have been specifically linked to critical developmental pathways, and the dysregulation of many miRNAs has been shown to have functional significance for various human diseases, including cardiovascular disorders, inflammatory diseases, infections, developmental disorders, neurodegenerative diseases and numerous types of cancers. ${ }^{26}$ In the context of cancers, dysregulated miRNAs have been reported to play either a tumor-suppressive or an oncogenic role in regulating tumor cell growth, cell cycle process, migration, angiogenesis and metastasis, depending on the function of their target genes. ${ }^{27}$ The identification of cancer-specific oncomiRs and their expression patterns and target genes is critical for understanding the molecular mechanisms of carcinogenesis and may be important for the identification of novel therapeutic targets and drugs and the development of effective screening and prevention tools. ${ }^{5,28,29}$

$\mathrm{miR}-23 \mathrm{a} / \mathrm{b}$ are involved in the regulation of a wide variety of cellular processes, including cell differentiation, proliferation, apoptosis, migration and cell-cycle distribution, and also play important roles in several types of human cancers with diverse effects. For example, Zhu et al ${ }^{30}$ reported significant upregulation of miR-23a in gastric adenocarcinoma tissues and demonstrated that miR-23a could target IL6R and promote growth in gastric adenocarcinoma cells. In contrast to $\mathrm{miR}-23 \mathrm{a}, \mathrm{miR}-23 \mathrm{~b}$ has a dual role in carcinogenesis and functions as either tumor promoter or tumor suppressor. ${ }^{31}$ In this study, we evaluated the expression patterns of miR-23a/b in gastric cancer tissues and observed that both miR-23a and miR-23b could function as an anti-apoptotic factor in gastric cancer cells. The findings that $\mathrm{miR}-23 \mathrm{a} / \mathrm{b}$ are co-upregulated in gastric cancer and have concordant cellular functions allowed us to hypothesize that the $\mathrm{miR}-23 \mathrm{a} / \mathrm{b}$ combination might play an important role in gastric carcinogenesis. Therefore, we looked for the target genes of $\mathrm{miR}-23 \mathrm{a} / \mathrm{b}$ and identified PDCD4 as a co-target. The results indicated that combined miR-23a/b overexpression may be involved in the progression of gastric cancer through co-targeting tumor suppressor PDCD4 in this malignancy. Consistent with this hypothesis, Li et al. ${ }^{31}$ also found that Fas is a co-target of $\mathrm{miR}-23 \mathrm{a} / \mathrm{b}$ in thymic lymphoma cells. In a future study, the clinical implications of the combined high expression of $\mathrm{miR}-23 \mathrm{a} / \mathrm{b}$ in cancer tissues should be evaluated. Theoretically, co-overexpression of miR-23a/b in cancer tissues may be associated with aggressive tumor progression and poor prognosis, and determining the expression patterns of miR$-23 a / b$ may help in elucidating the risk for cancer patients.

Many miRNAs work in conjunction with each other to finetune gene expression on a global level. To date, most research on miRNAs has focused on the role of individual miRNA in the regulation of a specific gene. It is important to study the cooperative role of multiple miRNAs, as this insight will give us a whole picture of miRNA regulation within the cell. Studies of the functions of co-expressed $\mathrm{miR}-23 \mathrm{a} / \mathrm{b}$ are a promising way to decipher the cooperative effects of multiple miRNAs. Although the reason for the co-expression of $m i R-23 a / b$ is not fully understood, a possibility is that the simultaneous upregulation or downregulation of $\mathrm{miR}-23 \mathrm{a} / \mathrm{b}$ is related to their cooperative effects in regulating specific genes and cellular 


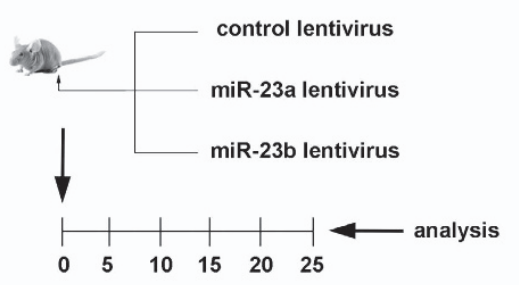

C

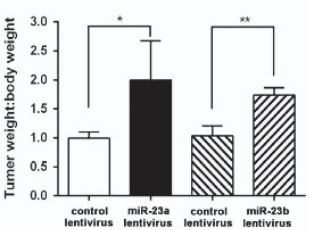

b
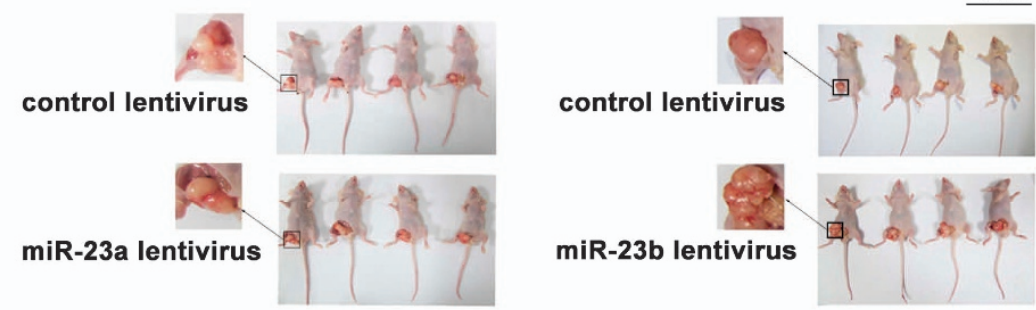

$5 \mathrm{CM}$

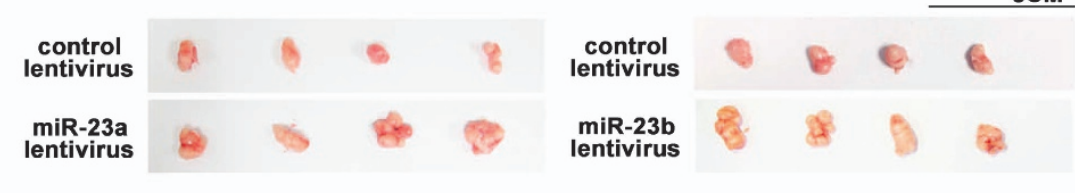

d

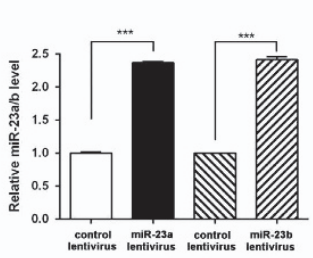

e

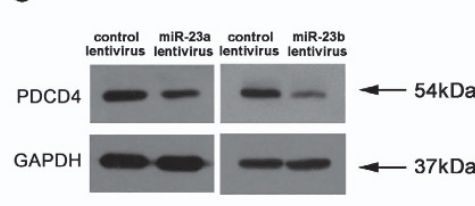

g

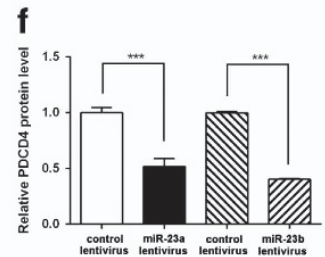

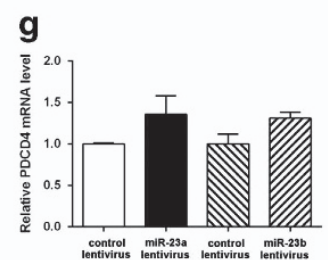

h
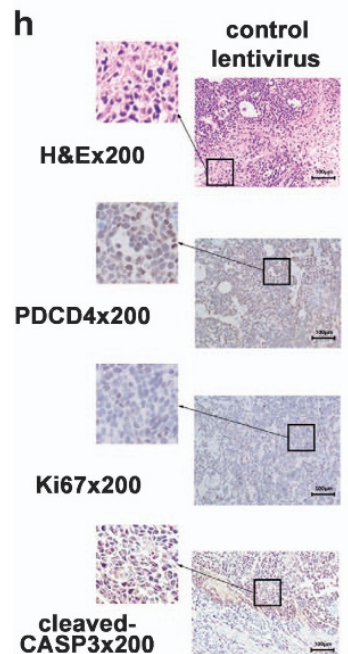
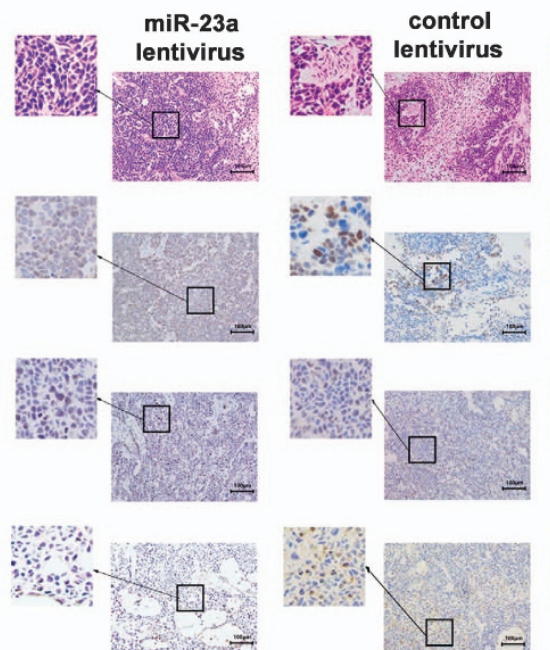

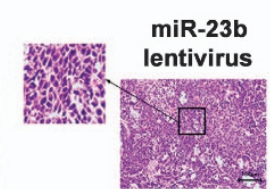

i
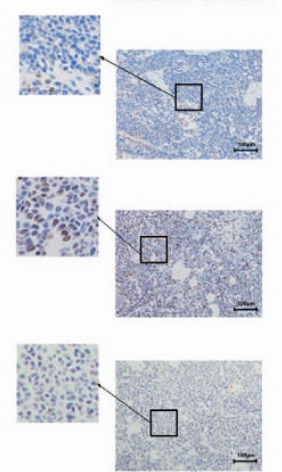

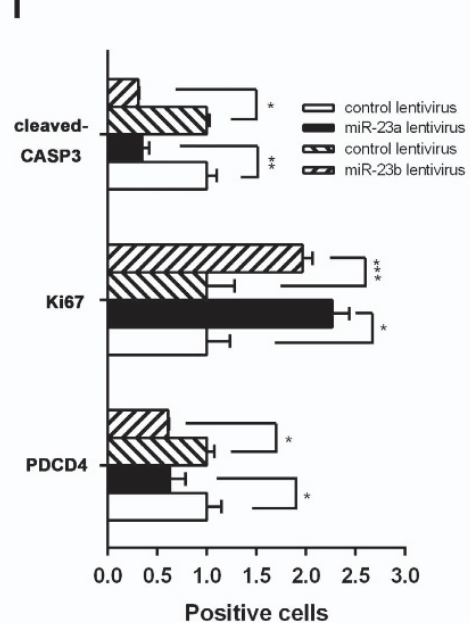

Figure 5 Effects of miR-23a/b on tumor growth in a gastric cancer xenograft mouse model. (a) Flow chart of the experimental procedure. MKN-45 cells were infected with a control lentivirus or lentiviruses to overexpress miR-23a or miR-23b. After infection, MKN-45 cells $\left(2 \times 10^{7}\right.$ cells per 0.1 ml) were subcutaneously implanted into 6 -week-old SCID mice (8 mice per group), and tumor growth was evaluated on day 25 after cell implantation. (b) Representative images of the implanted mice and tumors from the implanted mice. (c) Quantitative analysis of the tumor weights. (d) Quantitative RT-PCR analysis of miR-23a/b levels in the tumors from implanted mice. (e,f) Western blotting analysis of PDCD4 protein levels in the tumors from implanted mice. (e) representative image; (f) quantitative analysis. (g) Quantitative RT-PCR analysis of PDCD4 mRNA levels in the tumors from implanted mice. (h) Representative H\&E-stained, PDCD4-stained, Ki-67-stained and cleaved-CASP3-stained sections of the tumors from implanted mice. (i) Quantitative analysis of the sections. $\left({ }^{\star} P<0.05 ;{ }^{* \star} P<0.01 ;{ }^{* \star *} P<0.001\right)$

pathways. This type of regulation is important because when $\mathrm{miR}-23 \mathrm{a} / \mathrm{b}$ work in concert to repress a gene, the effect may be more efficient and potent than that by a single miRNA. On the other hand, co-regulation by miR-23a/b may be a fail-proof mode of miRNA regulation to ensure that when one member of the $\mathrm{miR}-23 \mathrm{a} / \mathrm{b}$ family is disabled by mutations or dysfunction, the other one is still available to exert its biological function. Cooperation among the miR-23a/b family thus provides an interesting area of study that may change our perception of how miRNAs mediate gene regulation.
Transcription factors (TFs) and miRNAs can jointly regulate target gene expression in the forms of feed-forward loops (FFLs) or feedback loops (FBLs). These regulatory loops serve as important motifs in gene regulatory networks and play critical roles in multiple biological processes and different diseases. Major progress has been made in bioinformatics and experimental study for the TF and miRNA co-regulation in recent years. Previous studies reported that miR-223 and three TFs (C/EBPa, NFI-A and E2F1) play critical roles in granulocyte differentiation and the occurrence of acute 
myelocytic leukemia. ${ }^{32} \mathrm{Ma}$ et al. $^{33}$ found a positive feedback loop comprised of KLF3 and miR-23a promoting the expression of $\beta$-like globin genes and the miR-23a/27a/24-2 cluster during erythropoiesis. He et al. ${ }^{34}$ revealed a positive feedback loop of PI3K-miR-19a, and MAPK-miR-23b/27b in endothelial cells under shear stress. We also showed that hypermethylated in cancer 1 ( $\mathrm{HIC1}$ ) and miR-23 27 24 clusters form a double-negative feedback loop in breast cancer. ${ }^{35}$ In this study, we predicted transcription factors that can potentially regulate $\mathrm{miR}-23 \mathrm{a} / \mathrm{b}$. Through bioinformatics analysis, we found some signaling pathways and transcription factors that may take part in regulation of $\mathrm{miR}-23 \mathrm{a} / \mathrm{b}$ and PDCD4. For example, PDCD4 has been reported to play a role as an inhibitor in AP-1 signaling pathway, ${ }^{36}$ and AP-1 signaling has been shown to activate miR-23a expression. ${ }^{37}$ Thus, AP-1/ miR-23a/PDCD4 is likely to form a double-negative (overall positive) feedback loop that contributes to gastric cancer progression. AP-1 downregulation leads to a decrease in miR-23a expression and subsequent PDCD4 activation, which in turn results in the depletion of AP-1 expression.

PDCD4 plays a pivotal tumor-suppression role in the occurrence and development of various cancers. In several types of human tumors, such as breast cancer ${ }^{38}$ and hepatocellular carcinoma, ${ }^{39}$ the levels of PDCD4 were significantly decreased or even disappeared in some tissues. It is generally thought that PDCD4 participates in tumorigenesis through the regulation of apoptosis. For example, Wang et al. ${ }^{40}$ confirmed that PDCD4 mediates the sensitivity of gastric cancer cells to apoptosis by suppressing FLIP, a negative regulator of apoptosis. In this study, we observed that PDCD4 was consistently reduced in gastric cancer tissues compared with normal adjacent tissues. We also provided evidence that PDCD4 functions as an essential pro-apoptotic factor in gastric cancer: silencing PDCD4 expression in gastric cancer cells through siRNA inhibits apoptosis, whereas overexpressing PDCD4 has a remarkable effect in promoting cell apoptosis. Interestingly, we identified discordance between PDCD4 protein and mRNA levels in human gastric cancer tissues, suggesting that a post-transcriptional regulatory mechanism is involved in PDCD4 repression. Because miRNA is an important mode of post-transcriptional regulation, we searched for miRNAs that target PDCD4 and validated the direct inhibition of PDCD4 translation through miR-23a/b. Furthermore, because miR-23a/b and PDCD4 had opposing effects on cell apoptosis, it is quite possible that $\mathrm{miR}-23 \mathrm{a} / \mathrm{b}$ suppressed PDCD4 expression and consequently inhibited cell apoptosis and promoted tumor growth during gastric cancer progression. Interestingly, we showed that the restoration of PDCD4 expression successfully attenuated the antiapoptotic effects of $\mathrm{miR}-23 \mathrm{a} / \mathrm{b}$ on gastric cancer cells, indicating that the targeting of PDCD4 may be a major mechanism through which $\mathrm{miR}-23 \mathrm{a} / \mathrm{b}$ exerted its antiapoptotic function. PDCD4, as a potent tumor suppressor, may serve as a potential new therapeutic target for gastric cancer, but technical limitations make it difficult to stably express PDCD4 in vivo. Because miR-23a/b are upstream regulators of PDCD4 and can specifically block the targeted PDCD4 mRNA with high efficiency and convenience, it is possible to downregulate miR-23a/b for restoration of PDCD4 expression in vivo. Currently, the correction of cellular miRNA levels has emerged as a potential therapeutic strategy for a broad range of diseases from genetic disorders to cancer and viral infection. ${ }^{41,42}$ Overexpression of miRNAs can be silenced using antagomirs, and re-expression of miRNAs that are lost in diseases can be achieved by the overexpression of miRNA mimics. ${ }^{43,44}$ For example, some scientists have already established the potential usefulness of miRNAs as therapeutic molecules against cancers, including the inhibition of cancer cell proliferation by miR-26a in a mouse model of hepatocellular carcinoma ${ }^{45}$ and the prevention of metastasis formation by silencing miR-10b. ${ }^{46}$ With improvements in nanocarrier technology, miRNA-based therapeutics leads to a greater number of medical breakthroughs and has the potential to generate a revolution in the treatment of diseases. ${ }^{47,48}$ Currently, delivery system utilizing liposomes, cationic polymer nanoparticles, synthetic chemical agents and native RNA transport service (e.g., exosome) are under active development. ${ }^{49}$ Further studies should be performed to characterize the feasibility of targeting $\mathrm{miR}-23 \mathrm{a} / \mathrm{b}$ in gastric cancer therapy and to develop simplified and cost-effective delivery system.

In summary, this study not only uncovered the critical roles of $\mathrm{miR}-23 \mathrm{a} / \mathrm{b}$ as oncomiRs in gastric cancer but also explored the molecular mechanisms through which miR-23a/b contributed to gastric cancer progression and identified PDCD4 as a direct target gene. Regulation of PDCD4 by miR-23a/b may explain why the upregulation of $\mathrm{miR}-23 \mathrm{a} / \mathrm{b}$ during gastric carcinogenesis promotes tumor growth. This study may provide insight into the molecular mechanism of gastric carcinogenesis and open a new avenue for gastric cancer treatment.

\section{Materials and Methods}

Human tissues and cell lines. A total of 10 pairs of gastric cancer tissues and normal adjacent tissues were derived from patients undergoing surgical procedures at the Affiliated Drum Tower Hospital of Nanjing University Medical School (Nanjing, China). All of the patients provided written consent and the Ethics Committee of Nanjing University approved all aspects of this study. Tissue fragments were immediately frozen in liquid nitrogen at the time of surgery and stored at $-80^{\circ} \mathrm{C}$. The clinical features of the patients are listed in Supplementary Table 1. The human gastric cancer cell lines MKN-45 and AGS were purchased from the Shanghai Institute of Cell Biology, Chinese Academy of Sciences (Shanghai, China). The cells were cultured in RPMI 1640 medium (Invitrogen, Carlsbad, CA, USA) supplemented with $10 \%$ fetal bovine serum (FBS, Gibco, Carlsbad, $\mathrm{CA}, \mathrm{USA}$ ) in a $5 \% \mathrm{CO}_{2}$ water-saturated atmosphere.

RNA extraction and quantitative RT-PCR. Total RNA was extracted from the human tissues and culture cells using Trizol reagent (Sigma, St. Louis, MO, USA) according to the manufacturer's instructions. The total RNA concentration was determined using a BioPhotometer (Eppendorf, Germany). Assays for the quantification of the miRNAs were performed using TaqMan miRNA probes (Applied Biosystems, Foster City, CA, USA) according to the manufacturer's instructions. Briefly, $1 \mu \mathrm{g}$ of total RNA was reverse-transcribed to CDNA using AMV reverse transcriptase (TaKaRa, Dalian, China) and a stem-loop RT primer (Applied Biosystems). The reaction conditions were as follows: $16^{\circ} \mathrm{C}$ for $30 \mathrm{~min}, 42^{\circ} \mathrm{C}$ for $30 \mathrm{~min}$ and $85^{\circ} \mathrm{C}$ for $5 \mathrm{~min}$. Real-time PCR was performed using a TaqMan PCR kit in an Applied Biosystems 7300 Sequence Detection System (Applied Biosystems). The reactions were incubated in a 96 -well optical plate at $95^{\circ} \mathrm{C}$ for $10 \mathrm{~min}$, followed by 40 cycles of $95^{\circ} \mathrm{C}$ for $15 \mathrm{~s}$ and $60^{\circ} \mathrm{C}$ for $1 \mathrm{~min}$. All of the reactions were run in triplicate. After the reaction, the cycle threshold $\left(\mathrm{C}_{\mathrm{T}}\right)$ data were determined using fixed threshold settings and the mean $C_{T}$ was determined from the triplicate PCRs. A comparative $C_{T}$ method was used to determine the relative levels of miRNAs. The amount of miRNA relative to the internal control U6 was calculated using the equation $2^{-\triangle \triangle C T}$, in which $\triangle \triangle \mathrm{C}_{\mathrm{T}}=\left(\mathrm{C}_{\mathrm{T}} \text { miR-23a/b }-\mathrm{C}_{\mathrm{T}} \text { U6 }\right)_{\text {tumor }}{ }^{-}$ $\left(\mathrm{C}_{\mathrm{T} \text { miR-23a/b }}-\mathrm{C}_{\mathrm{T}} \mathrm{U} 6\right)_{\text {control. }}$ 
To quantify PDCD4 mRNA, $1 \mu \mathrm{g}$ of total RNA was reverse-transcribed to CDNA using oligo dTand AMV reverse transcriptase (TaKaRa, Dalian, China) in the reaction, which was performed using the following conditions: $42{ }^{\circ} \mathrm{C}$ for 60 min and $70{ }^{\circ} \mathrm{C}$ for $10 \mathrm{~min}$. Next, real-time PCR was performed with the RT product, SYBER Green Dye (Invitrogen, Carlsbad, CA, USA) and specific primers for PDCD4 and GAPDH. The sequences of the primers were as follows: PDCD4 (sense): $5^{\prime}$-GTTGGCAGTA TCCTTAGCATTGG-3'; PDCD4 (antisense): 5'-TCCACATCAGTTGTGCTCATTAC-3'; GAPDH (sense): 5'-GATATTGTTGCCATCAATGAC-3'; and GAPDH (antisense): $5^{\prime}$-TTGATTTTGGAGGGATCTCG- 3 '. The reactions were incubated at $95^{\circ} \mathrm{C}$ for 5 min, followed by 40 cycles of $95^{\circ} \mathrm{C}$ for $30 \mathrm{~s}, 60^{\circ} \mathrm{C}$ for $30 \mathrm{~s}$ and $72^{\circ} \mathrm{C}$ for $30 \mathrm{~s}$. After the reactions were complete, the $C_{T}$ values were determined by setting a fixed threshold. The relative amount of PDCD4 mRNA was normalized to GAPDH.

Protein extraction and western blotting. Total protein was extracted from the human tissues and culture cells using the RIPA lysis buffer (Beyotime, Shanghai, China) according to the manufacturer's instructions. The supernatant was collected, and the protein concentration was calculated with a Pierce BCA protein assay kit (Thermo Scientific, Rockford, IL, USA). Then, equivalent quantities of protein were separated by $10 \%$ SDS-PAGE and transferred to a PVDF membrane (Millipore, Bedford, MA, USA). After blocking with 5\% non-fat milk at room temperature for $1 \mathrm{~h}$, the membranes were immunostained with a primary antibody at $4{ }^{\circ} \mathrm{C}$ overnight, washed three times in TBST, and then incubated with a secondary antibody at room temperature for $1 \mathrm{~h}$. The band signals were detected with an enhanced chemiluminescence reagent (Cell Signaling Technology Inc., USA). The protein levels were normalized by probing the same blots with a GAPDH antibody. The primary antibodies were purchased from the following sources: anti-PDCD4 (Santa Cruz, CA, USA); anti-GAPDH (Santa Cruz, CA, USA); anti-cleaved-CASP9 (Cell Signaling Technology Inc., USA); anti-cleaved-CASP3 (Cell Signaling Technology Inc., USA); anti-cleaved-CASP6 (Cell Signaling Technology Inc., USA); anti-cleaved-CASP7 (Cell Signaling Technology Inc., USA); anti-cleavedCASP9 (Cell Signaling Technology Inc., USA); and anti-cleaved-PARP (Cell Signaling Technology Inc., USA). The intensity of each band was scanned and quantified using imageJ software.

Overexpression or knockdown of $\mathrm{miR}-23 \mathrm{a} / \mathrm{b}$. Overexpression of miR-23a/b was achieved by transfecting gastric cancer cells with miRNA mimics (synthetic RNA oligonucleotides mimicking precursors of miR-23a/b). Knockdown of miR-23a/b was achieved by transfecting with miRNA inhibitors (chemically modified single-stranded antisense oligonucleotides designed to specifically sequester mature miR-23a/b). Synthetic miR-23a/b mimics (pre-miR-23a/b), inhibitors (antimiR-23a/b) and scrambled negative control RNAs (pre-miR-control and anti-miRcontrol) were purchased from GenePharma (Shanghai, China). MKN-45 and AGS cells were seeded in 6-well plates using RPMl 1640 medium supplemented with $10 \%$ FBS. The cells were transfected with Lipofectamine 2000 (Invitrogen, Carlsbad, CA, USA) using Opti-MEM Reduced Serum Medium (Gibco, Carlsbad, CA, USA) on the following day when the cells were $\sim 60-70 \%$ confluent. For each well, equal amounts of pre-miR-23a/b, pre-miR-control, anti-miR-23a/b or anti-miRcontrol were used. After $6 \mathrm{~h}$, the medium was changed to RPMl 1640 supplemented with $2 \%$ FBS. The cells were collected at 24 or $48 \mathrm{~h}$ after transfection and subjected to analysis by quantitative RT-PCR or western blotting.

SiRNA interference and plasmid construction. SiRNA sequence targeting the human PDCD4 cDNA was designed and synthesized by GenePharma. The siRNA sequence was as follows: 5'-GCGGAAAUGUUAAGAGAUU-3'. A scrambled siRNA was synthesized as a negative control. A mammalian expression plasmid encoding the full-length human PDCD4 open reading frame (ORF) without the miR-23a/ b-responsive $3^{\prime}$-UTR was purchased from Invitrogen. An empty plasmid was used as the negative control. The PDCD4 siRNA and the PDCD4 expression plasmid were transfected into MKN-45 cells using Lipofectamine 2000 (Invitrogen, Carlsbad, CA, USA) according to the manufacturer's instructions. Total RNA and protein were isolated $24 \mathrm{~h}$ post-transfection. The PDCD4 mRNA and protein expression levels were assessed by quantitative RT-PCR and western blotting, respectively.

Luciferase reporter assays. The entire $3^{\prime}$-UTR of the human PDCD4 transcript was amplified by PCR using human genomic DNA as a template. The PCR products were inserted into the p-MIR-reporter plasmid (Ambion, Austin, TX, USA). The insertion was confirmed as correct by sequencing. To test the binding specificity, the sequences that interact with the miR-23a/b seed sequence were mutated, and the mutant PDCD4 $3^{\prime}$-UTR was inserted into an equivalent luciferase reporter. For the luciferase reporter assay, HEK293T cells were cultured in 24-well plates. Each well was transfected with $0.2 \mu \mathrm{g}$ of firefly luciferase reporter plasmid, $0.1 \mu \mathrm{g}$ of a $\beta$-galactosidase ( $\beta$-gal) expression plasmid (Ambion), and equal amounts $100 \mathrm{pmol}$ of pre-miR-23a/b, anti-miR-23a/b or the scrambled negative control RNAs using Lipofectamine 2000 (Invitrogen, Carlsbad, CA, USA). The $\beta$-gal plasmid was used as a transfection control. The cells were assayed using a luciferase assay kit (Promega, Madison, WI, USA) at $24 \mathrm{~h}$ post transfection.

Cell apoptosis assays. The apoptosis of MKN- 45 cells was examined using an Annexin V-FITC/propidium iodide (PI) staining assay. MKN-45 cells were cultured in 12-well plates and transfected with pre-miR-23a/b, anti-miR-23a/b, PDCD4 siRNA or PDCD4-overexpression plasmid. Pre-miR-control, anti-miR-control, control siRNA and control plasmids served as negative controls. The cells were cultured in serumdepleted medium to induce apoptosis. After $24 \mathrm{~h}$, the floating cells were discarded, and the attached cells were collected. The apoptotic cells were identified through flow cytometry using an Annexin V-FITC/PI staining kit (BD Biosciences, CA, USA). After washing with cold PBS, the cells were re-suspended in binding buffer $(100 \mathrm{mM}$ HEPES, pH 7.4, $100 \mathrm{mM} \mathrm{NaCl}$, and $25 \mathrm{mM} \mathrm{CaCl}$ ), followed by staining with Annexin V-FITC/PI at room temperature for $15 \mathrm{~min}$ in the dark. Apoptotic cells were subsequently evaluated by gating $\mathrm{Pl}$ and Annexin V-positive cells on a fluorescenceactivated cell-sorting (FACS) flow cytometer (BD Biosciences, San Jose, CA). All experiments were performed in triplicate.

Establishment of tumor xenografts in mice. Six-week-old male SCID (severe combined immune deficiency) mice ( $n u / n u$ ) were purchased from the Model Animal Research Center of Nanjing University (Nanjing, China) and were maintained under specific pathogen-free conditions at Nanjing University. MKN-45 cells were infected with a control lentivirus or lentiviruses to overexpress miR-23a or miR-23b. After infection and transfection, MKN-45 cells were subcutaneously injected into xenograft mice $\left(2 \times 10^{7}\right.$ cells per mouse, 8 mice per group). After 25 days, the mice were killed. The tumor xenografts were removed, and the weight of the tumors was measured. Parts of the tumors were used for protein and total RNA extraction, and the remaining tumors were fixed in $4 \%$ paraformaldehyde for $24 \mathrm{~h}$ and then processed for hematoxylin and eosin (H\&E) staining or immunohistochemical staining for PDCD4, Ki-67 and cleaved-CASP3.

Statistical analysis. All images of western blotting and cell apoptosis assays are representatives of at least three independent experiments. Quantitative RT-PCR and luciferase reporter assays were performed in triplicate, and each experiment was repeated three to five times. The data shown are the mean \pm SD of at least three independent experiments. The differences were considered statistically significant at $P<0.05$ using Student's t-test. Prism 5.0 software (GraphPad, Inc., La Jolla, CA, USA) was used for data analyzes.

\section{Conflict of Interest}

The authors declare no conflict of interest.

Acknowledgements. This work was supported by grants from the National Basic Research Program of China (973 Program) (No. 2014CB542300), the National Natural Science Foundation of China (No. 81602697), the Natural Science Foundation of Jiangsu Province (No. BE2016737) and Fundamental Research Funds for the Central Universities (No. 020814380070).

\section{Author contributions}

$X C$ designed the project. $X H$ and $Y W$ designed the experiments. $X H, Y W, H L, Q F, R Z$ and JC performed the experiments. WZ provided the human samples. KZ, C-YZ, DH, $\mathrm{ZZ}$ and $\mathrm{XC}$ wrote the manuscript.

\section{Publisher's Note}

Springer Nature remains neutral with regard to jurisdictional claims in published maps and institutional affiliations.

1. Torre LA, Bray F, Siegel RL, Ferlay J, Lortet-Tieulent J, Jemal A. Global cancer statistics, 2012. CA Cancer J Clin 2015; 65: 87-108.

2. Lansdorp-Vogelaar I, Kuipers EJ. Screening for gastric cancer in Western countries. Gut 2016; 65: 543-544 
3. Song B, Zhan H, Bian Q, Gu J. Piperlongumine inhibits gastric cancer cells via suppression of the JAK1,2/STAT3 signaling pathway. Mol Med Rep 2016; 13: 4475-4480.

4. Lund E, Guttinger S, Calado A, Dahlberg JE, Kutay U. Nuclear export of microRNA precursors. Science 2004; 303: 95-98.

5. Bartel DP. MicroRNAs: genomics, biogenesis, mechanism, and function. Cell 2004; 116 : 281-297.

6. Lee RC, Ambros V. An extensive class of small RNAs in Caenorhabditis elegans. Science 2001; 294: 862-864.

7. Lagos-Quintana M, Rauhut R, Lendeckel W, Tuschl T. Identification of novel genes coding for small expressed RNAs. Science 2001; 294: 853-858.

8. Kloosterman WP, Plasterk RH. The diverse functions of microRNAs in animal development and disease. Dev Cell 2006; 11: 441-450.

9. Wijnhoven BP, Michael MZ, Watson DI. MicroRNAs and cancer. Br J Surg 2007; 94: 23-30.

10. Jahid S, Sun J, Edwards RA, Dizon D, Panarelli NC, Milsom JW et al. miR-23a promotes the transition from indolent to invasive colorectal cancer. Cancer Discov 2012; 2: 540-553.

11. Donadelli M, Dando I, Fiorini C, Palmieri M. Regulation of miR-23b expression and its dual role on ROS production and tumour development. Cancer Lett 2014; 349: 107-113.

12. Mi S, Lu J, Sun M, Li Z, Zhang H, Neilly MB et al. MicroRNA expression signatures accurately discriminate acute lymphoblastic leukemia from acute myeloid leukemia. Proc Natl Acad Sci USA 2007; 104: 19971-19976.

13. Gottardo F, Liu CG, Ferracin M, Calin GA, Fassan M, Bassi $P$ et al. Micro-RNA profiling in kidney and bladder cancers. Urol Oncol 2007; 25: 387-392.

14. Ciafre SA, Galardi S, Mangiola A, Ferracin M, Liu CG, Sabatino G et al. Extensive modulation of a set of microRNAs in primary glioblastoma. Biochem Biophys Res Commun 2005; 334: 1351-1358.

15. Marsh EE, Lin Z, Yin P, Milad M, Chakravarti D, Bulun SE. Differential expression of microRNA species in human uterine leiomyoma versus normal myometrium. Fertil Steril 2008; 89: 1771-1776

16. Huang S, He X, Ding J, Liang L, Zhao Y, Zhang Z et al. Upregulation of miR-23a approximately 27 a approximately 24 decreases transforming growth factor-beta-induced tumor-suppressive activities in human hepatocellular carcinoma cells. Int J Cancer 2008; 123: 972-978.

17. Volinia S, Calin GA, Liu CG, Ambs S, Cimmino A, Petrocca F et al. A microRNA expression signature of human solid tumors defines cancer gene targets. Proc Natl Acad Sci USA 2006; 103: 2257-2261

18. Lewis BP, Shih $\mathrm{IH}$, Jones-Rhoades MW, Bartel DP, Burge CB. Prediction of mammalian microRNA targets. Cell 2003; 115: 787-798.

19. Krek A, Grun D, Poy MN, Wolf R, Rosenberg L, Epstein EJ et al. Combinatorial microRNA target predictions. Nat Genet 2005; 37: 495-500.

20. John B, Enright AJ, Aravin A, Tuschl T, Sander C, Marks DS. Human MicroRNA targets. PLOS Biol 2004; 2: e363.

21. Yuan $T$, Wang $Y$, Zhao ZJ, Gu H. Protein-tyrosine phosphatase PTPN9 negatively regulates ErbB2 and epidermal growth factor receptor signaling in breast cancer cells. J Biol Chem 2010; 285: 14861-14870.

22. Su F, Ren F, Rong Y, Wang Y, Geng Y, Wang $Y$ et al. Protein tyrosine phosphatase Meg2 dephosphorylates signal transducer and activator of transcription 3 and suppresses tumor growth in breast cancer. Breast Cancer Res 2012; 14: R38.

23. Jin H, Kim TH, Hwang SK, Chang SH, Kim HW, Anderson HK et al. Aerosol delivery of urocanic acid-modified chitosan/programmed cell death 4 complex regulated apoptosis, cell cycle, and angiogenesis in lungs of K-ras null mice. Mol Cancer Ther 2006; 5: 1041-1049.

24. Crowley LC, Waterhouse NJ. Detecting cleaved caspase-3 in apoptotic cells by flow cytometry. Cold Spring Harbor protoc 2016; 2016: pdb.prot087312.

25. Zhen Y, Liu Z, Yang H, Yu X, Wu Q, Hua S et al. Tumor suppressor PDCD4 modulates miR-184-mediated direct suppression of C-MYC and BCL2 blocking cell growth and survival in nasopharyngeal carcinoma. Cell Death Disease 2013; 4: e872.

26. Garzon R, Calin GA, Croce CM. MicroRNAs in cancer. Ann Rev Medicine 2009; 60: 167-179.

27. Esquela-Kerscher A, Slack FJ.. Oncomirs - microRNAs with a role in cancer. Nat Rev Cancer 2006; 6: 259-269.

28. Bartel DP. MicroRNAs: target recognition and regulatory functions. Cell 2009; 136: 215-233

29. Chen CZ, Li L, Lodish HF, Bartel DP. MicroRNAs modulate hematopoietic lineage differentiation. Science 2004; 303: 83-86.

30. Zhu L, Jin L, Jiang R, Wang Q, Jiang J, Mao C et al. Correlations between miRNAs and TGFbeta1 in tumor microenvironment of esophageal squamous cell cancer. Chin $\mathrm{J}$ Cell Mol Immunol 2013; 29: 524-528.

31. Li B, Sun M, Gao F, Liu W, Yang Y, Liu H et al. Up-regulated expression of miR-23a/b targeted the pro-apoptotic Fas in radiation-induced thymic lymphoma. Cell Physiol Biochem: Int J Exp Cell Physiol, Biochem, Pharmacol 2013; 32: 1729-1740.
32. Li X, Zhang $Y$, Zhang $H$, Liu X, Gong T, Li M et al. miRNA-223 promotes gastric cancer invasion and metastasis by targeting tumor suppressor EPB41L3. Mol Cancer Res 2011; 9 : 824-833.

33. Ma Y, Wang B, Jiang F, Wang D, Liu H, Yan Y et al. A feedback loop consisting of microRNA 23a/27a and the beta-like globin suppressors KLF3 and SP1 regulates globin gene expression. Mol Cell Biol 2013; 33: 3994-4007.

34. He J, Li Y, Yang X, He X, Zhang H, He J et al. The feedback regulation of PI3K-miR-19a, and MAPK-miR-23b/27b in endothelial cells under shear stress. Molecules 2012; 18: $1-13$.

35. Wang $\mathrm{Y}$, Liang H, Zhou G, Hu X, Liu Z, Jin F et al. HIC1 and miR-23 27 24 clusters form a double-negative feedback loop in breast cancer. Cell Death Differ 2017; 24: 421-432.

36. Wang Q, Sun Z, Yang HS.. Downregulation of tumor suppressor Pdcd4 promotes invasion and activates both beta-catenin/Tcf and AP-1-dependent transcription in colon carcinoma cells. Oncogene 2008; 27: 1527-1535.

37. Zheng H, Li W, Wang Y, Xie T, Cai Y, Wang Z et al. miR-23a inhibits E-cadherin expression and is regulated by AP-1 and NFAT4 complex during Fas-induced EMT in gastrointestinal cancer. Carcinogenesis 2014; 35: 173-183.

38. Chen Z, Yuan YC, Wang Y, Liu Z, Chan HJ, Chen S. Down-regulation of programmed cell death 4 (PDCD4) is associated with aromatase inhibitor resistance and a poor prognosis in estrogen receptor-positive breast cancer. Breast Cancer Res Treat 2015; 152 : 29-39.

39. Ding X, Cheng X, Gong M, Chen X, Yin F, Lai K. Hypermethylation and expression silencing of PDCD4 gene in hepatocellular carcinoma: a consort study. Medicine 2016; 95: e2729.

40. Wang W, Zhao J, Wang H, Sun Y, Peng Z, Zhou G et al. Programmed cell death 4 (PDCD4) mediates the sensitivity of gastric cancer cells to TRAlL-induced apoptosis by downregulation of FLIP expression. Exp Cell Res 2010; 316: 2456-2464.

41. Perera RJ, Ray A. MicroRNAs in the search for understanding human diseases. BioDrugs: Clin Immunother, Biopharm Gene Ther 2007; 21: 97-104.

42. Ojha CR, Rodriguez M, Dever SM, Mukhopadhyay R, El-Hage N. Mammalian microRNA: an important modulator of host-pathogen interactions in human viral infections. J Biomed Sci 2016; 23: 74

43. Nan YH, Wang Y, Sun PH, Han Y, Fan L, Wang KC et al. MiR-6838 promotes growth and invasion in bladder cancer via suppression of Rb. Oncol Res 2017.

44. Henshall DC. Manipulating microRNAs in murine models: targeting the multi-targeting in epilepsy. Epilepsy Curr 2017; 17: 43-47.

45. Kota J, Chivukula RR, O'Donnell KA, Wentzel EA, Montgomery CL, Hwang HW et al. Therapeutic microRNA delivery suppresses tumorigenesis in a murine liver cancer model. Cell 2009; 137: 1005-1017.

46. Ma L, Reinhardt F, Pan E, Soutschek J, Bhat B, Marcusson EG et al. Therapeutic silencing of miR-10b inhibits metastasis in a mouse mammary tumor model. Nat Biotechnol 2010; 28: 341-347.

47. Wang V, Wu W. MicroRNA-based therapeutics for cancer. BioDrugs : Clin Immunother, Biopharm Gene Ther 2009; 23: 15-23.

48. Mencia Castano I, Curtin CM, Shaw G, Murphy JM, Duffy GP, O'Brien FJ. A novel collagennanohydroxyapatite microRNA-activated scaffold for tissue engineering applications capable of efficient delivery of both miR-mimics and antagomiRs to human mesenchymal stem cells. $J$ Control Release 2015; 200: 42-51.

49. Zhang D, Lee H, Zhu Z, Minhas JK, Jin Y. Enrichment of selective miRNAs in exosomes and delivery of exosomal miRNAs in vitro and in vivo. Am J Physiol Lung Cell Mol Physiol 2017; 312: L110-L121.

(i) Cell Death and Disease is an open-access journal (c) published by Nature Publishing Group. This work is licensed under a Creative Commons Attribution 4.0 International License. The images or other third party material in this article are included in the article's Creative Commons license, unless indicated otherwise in the credit line; if the material is not included under the Creative Commons license, users will need to obtain permission from the license holder to reproduce the material. To view a copy of this license, visit http://creativecommons.org/licenses/by/4.0/

(C) The Author(s) 2017 